\title{
Nano Phase Characterization by Transmission Electron Microscopy: Experimental and Simulation
}

\author{
Francisco Miguel Ascencio Aguirre1, Lourdes Bazán-Díaz¹, Rubén Mendoza-Cruz, \\ Alfredo Gómez-Rodríguez ${ }^{2}$, Cristina Zorrilla-Cangas ${ }^{2}$, Raúl Herrera-Becerra ${ }^{2 *}$ \\ ${ }^{1}$ Posgrado en Ciencia e Ingeniería de Materiales, Instituto de Física, UNAM, Circuito de la Investigación \\ Científica, Ciudad Universitaria, México, D.F., México \\ ${ }^{2}$ Departamento de Materia Condensada/Instituto de Física, UNAM, Circuito de la Investigación Científica, \\ Ciudad Universitaria, México, D.F., México \\ Email: fascencio@fisica.unam.mx
}

Received 4 August 2015; accepted 3 November 2015; published 6 November 2015

Copyright (C) 2015 by authors and Scientific Research Publishing Inc.

This work is licensed under the Creative Commons Attribution International License (CC BY). http://creativecommons.org/licenses/by/4.0/

(c) $\underset{\mathrm{EY}}{\mathrm{P}}$ Open Access

\begin{abstract}
This paper introduces a methodology of characterization of nanostructured systems in which transmission electron microscopy is used as a central element of the study. Experimental studies of HREM are performed in parallel with studies in the Simula TEM program to stimulate high-resolution images and diffraction patterns. To confirm the accuracy of the results, studies of $\mathrm{X}$-ray diffraction (XRD) were performed. In order to illustrate the methodology, bismuth oxide $\mathrm{Bi}_{2} \mathrm{O}_{3}$ nanoparticles are synthesized by a method of biosynthesis because this sample is rich in structural information.
\end{abstract}

\section{Keywords}

Transmission Electron Microscopy, Nanoparticles, Bismuth Oxide $\mathrm{Bi}_{2} \mathrm{O}_{3}$

\section{Introduction}

Transmission electron microscopy (TEM) is a powerful technique that allows us to form images and diffraction patterns from diverse nanomaterials. These images can be used to determine the morphological and structural features of the samples under study. However, what in practice is needed is a full structural characterization of the samples. For this task, techniques such as X-ray diffraction (XRD), high resolution TEM (HRTEM), optical spectroscopy, Raman spectroscopy, infrared spectroscopy (IR) and fluorescence analysis must be used. All these

\footnotetext{
${ }^{*}$ Corresponding author.
}

How to cite this paper: Aguirre, F.M.A., Bazán-Díaz, L., Mendoza-Cruz, R., Gómez-Rodríguez, A., Zorrilla-Cangas, C. and Herrera-Becerra, R. (2015) Nano Phase Characterization by Transmission Electron Microscopy: Experimental and Simulation. Materials Sciences and Applications, 6, 935-942. http://dx.doi.org/10.4236/msa.2015.611094 
in addition to the physical and chemical information are already available.

In this work, we describe a structural characterization of nanoparticles based on high resolution TEM images using our own software as well as commercial programs. To achieve this goal we study the synthesis of bismuth oxide particles through a biosynthesis method, using tannic acid as reducing agent, since these samples are very rich in structural details. Nowadays several research groups work on the synthesis of nanoparticles with technological applications using novel preparation methods, preferably those that are cheap end environmentally friendly. One of the interesting materials is bismuth oxide $\mathrm{Bi}_{2} \mathrm{O}_{3}$, which has many applications including medical ones since the $\alpha-\mathrm{Bi}_{2} \mathrm{O}_{3}$ phase due shows fungicidal activity against Candida Albicans [1] and also selectivity detection of $\mathrm{NO}$ as gas sensor [2], etc. In its most stable phase, $\alpha-\mathrm{Bi}_{2} \mathrm{O}_{3}$ is a p-type semiconductor [3] that has been synthetized by several methods such as: hydrothermal [4], sol-gel [5], laser ablation [6] [7], Bismuth oxidation [8], microwaves [9], micro emulsion [10], PEG Precipitation [11].

\section{Sample Preparation}

In order to prepare our samples, we use a small variation of the method of synthesis previously published [12]. In this method where used tannic acid $\left(\mathrm{C}_{76} \mathrm{H}_{52} \mathrm{O}_{46}\right)$ and bismuth nitrate pentahydrate $\mathrm{Bi}\left(\mathrm{NO}_{3}\right)_{3} * 5 \mathrm{H}_{2} \mathrm{O}$, the $\mathrm{pH}$ value was changed with $\mathrm{NaOH}$ and stabilized in $\mathrm{pH}=11$ in order to obtain a more alkaline environment in the synthesis to continue the process of lyophilization [13]. Yellow-brown powder was obtained from which the samples for both HRTEM and XRD were prepared.

The microscopy characterization was done with a JEOL JEM-2010F FasTem microscope operating at $200 \mathrm{kV}$ with a spherical aberration coefficient $\mathrm{Cs}=0.5 \mathrm{~mm}$ and fitted with analytical facilities. The X-ray measurements were carried out with a D8 Advance Bruker AXS diffractometer with $\mathrm{CuK}_{\alpha}$ radiation. The X-ray Diffraction Pattern was measured in the $2 \theta$ range from $4^{\circ}$ to $130^{\circ}$ with a step $0.019^{\circ}$.

For image processing and indexing of the nanoparticles, the computer programs Digital Micrograph and Diffraction Pattern Indexing Program (DPIP) [14] were used. Simulation of the nanoparticle morphology, TEM images and electron diffraction patterns was done with SimulaTEM [15], Materials Studio Version 2.1.5 and CaRiNe version 4.0 software.

\section{Procedure}

The procedure followed is shown in a schematic way in Figure 1. The starting point is a high resolution image obtained from the Transmission Electron Microscope, and then the digital Fast Fourier transform (FFT) of the image (or of a desired part thereof) was obtained with the help of the commercial Digital Micrograph software. From this diffractogram we select at least two different spots and the $(x, y)$ coordinates (with respect to a given rectangular coordinate system) are obtained. The center of the pattern is taken as the origin $(0,0)$ of the reference frame.

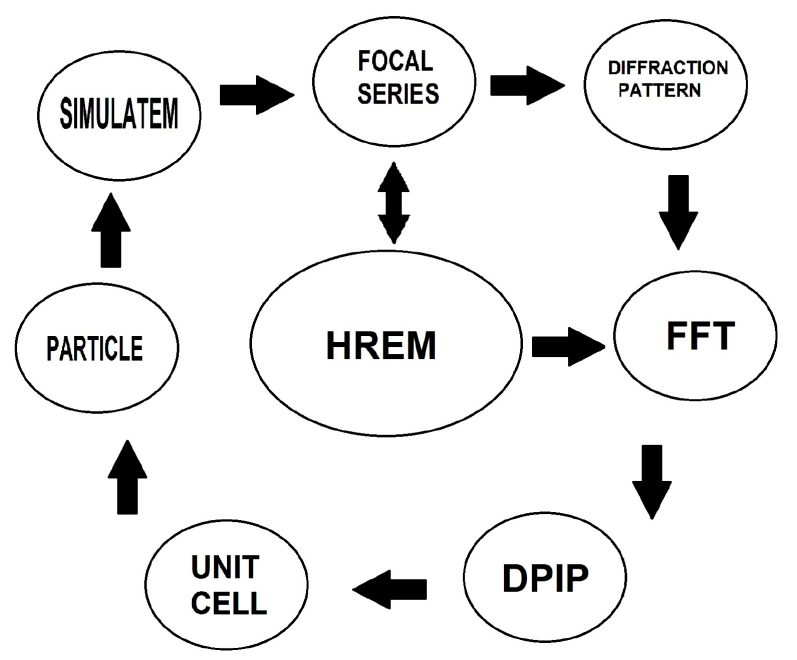

Figure 1. Sketch of the proposed analysis scheme. 
In the next stage we use our own tool DPIP to which we feed the relevant diffraction data from the powder diffraction files (such as $h, k, l$ reflections and intensities, lattice parameters of the candidate structures, etc). We also input the $(x, y)$ coordinates of the spots from the diffractogram and we select tolerance limits $\Delta a n g l e$ and $\Delta$ distance (the difference between measured and calculated values).

DPIP provides the zone axis and the Miller indexes of the lattice planes considered that best match the measured spots. The program considers as many structures as needed (each represented by its x-ray table) but takes into account only solutions within the established error limits ( $\Delta$ angle and $\Delta$ distance).

The next step is to calculate the coordinates of all the atoms in a cluster of the same size as the actual cluster in the original image. For this, we use data from the literature and sometimes we are assisted by Materials Studio. The structure calculated is based on the identification provided by DPIP software.

After this, we feed the structure to SimulaTEM with which we can simulate images and diffraction patterns using the multislice method [16]. The input in this case consists of the coordinates $(x, y, z)$ and atomic number of each atom together with the operating conditions of the microscope (accelerating voltage, spherical aberration etc.).

Once the data are introduced, the particle is oriented along the desired zone axes. Then focal series are calculated in a neighborhood of the Scherzer defocus condition. The procedure is repeated as many times as desired depending on how many zone axes and structure solutions are given by DPIP software. Finally the calculated and observed images are compared. Once the best matches are obtained we calculate the corresponding diffraction patterns for comparison with the diffractograms. The CaRiNe 4.0 software can be used to verify that the indexing is consistent and in agreement with the geometry (space group) of the sample.

\section{Results}

Here a full example of the procedure is shown outlined above where we want to identify a phase present in a particle starting with a HREM image (obtained with a JEOL JEM-2010F microscope).

Figure 2(A) shows the experimental image; Figure 2(B) presents an enlarged view of the selected particle, and finally Figure 2(C) displays the corresponding FFT (diffractogram). As described before, the images Figure 2(B) and Figure 2(C) were obtained with the help of the Digital Micrograph software.

For this example we selected the spots encircled in the figure. With Digital Micrograph the positions $(x, y)$ of the spots are measured. $((0,0)$ is assigned to the center of the diffractogram).

Given the preparation procedure, the nanoparticle is expected to be one of the possible bismuth oxides such as $\mathrm{BiO}$ [17], $\mathrm{Bi}_{2} \mathrm{O}_{3}$ [18], $\mathrm{Bi}_{2} \mathrm{O}_{4}$ [19], among others, but the most interesting is $\mathrm{Bi}_{2} \mathrm{O}_{3}$ due the polymorphs that this oxide presents, and their possible applications.

We considered the $\mathrm{Bi}_{2} \mathrm{O}_{3}$ polymorphs $\alpha-\mathrm{Bi}_{2} \mathrm{O}_{3}$ (Monoclinic,) [20], $\beta$ - $\mathrm{Bi}_{2} \mathrm{O}_{3}$ (Tetragonal) [21], $\gamma-\mathrm{Bi}_{2} \mathrm{O}_{3}(\mathrm{BCC})$ [22], $\delta$ - $\mathrm{Bi}_{2} \mathrm{O}_{3}$ (FCC) [23] and $\mathrm{H}_{-} \mathrm{Bi}_{2} \mathrm{O}_{3}$ (hexagonal) [24] respectively. The crystallographic information for each of these is taken from the Powder Diffraction Files. PCPDFWIN x-ray card (version 2.2, 2003). Table 1 shows these data.

With the positions of the spots and the known crystallographic data of the candidate structures we index the diffractograms using an error bound of $\Delta$ angle and $\Delta$ distance less than 1.1 degrees and $0.5 \AA$. After running DPIP for each of the polymorphs described above and for pure Bi (Monoclinic) [25]. We find that the smallest error of $\Delta$ angle corresponds to the $\delta$ - $\mathrm{Bi}_{2} \mathrm{O}_{3}$ phase (77-0374). However, this phase present a $\Delta$ distance out of the error limits that we set; so that this solution was not taken. In the same way, the error limit in $\Delta a n g l e$ was higher than the permitted error for phases such as Bi monoclinic (65-6203), Bi rombohedral (05-0519) and $\mathrm{H}_{-} \mathrm{Bi}_{2} \mathrm{O}_{3}$ (51-1161). At this stage, the remained possibilities are $\alpha-\mathrm{Bi}_{2} \mathrm{O}_{3}$ and $\beta-\mathrm{Bi}_{2} \mathrm{O}_{3}$, so the analysis is now limited to

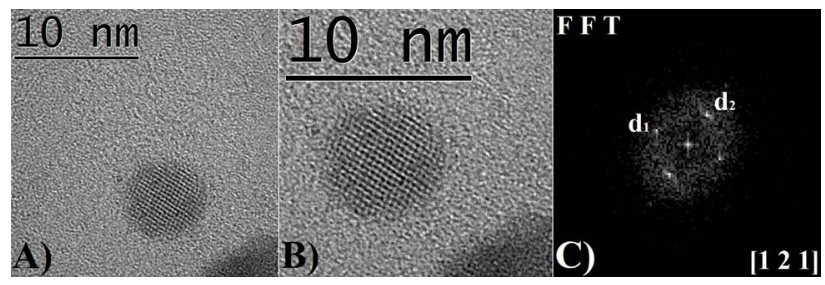

Figure 2. (A) HREM image of the particle under study; (B) Enlarged view; and (C) Corresponding FFT. 
Table 1. DPIP solutions for the $\beta-\mathrm{Bi}_{2} \mathrm{O}_{3}$ phase.

\begin{tabular}{|c|c|c|c|c|c|c|c|c|c|}
\hline \multirow{2}{*}{ Phase } & \multirow{2}{*}{ Angle } & \multirow{2}{*}{$\Delta$ angle } & \multirow{2}{*}{$\mathbf{k}_{1}$} & \multirow{2}{*}{$\Delta d_{1}$} & \multirow{2}{*}{$\mathbf{k}_{2}$} & \multirow{2}{*}{$\Delta \mathbf{d}_{2}$} & \multicolumn{3}{|c|}{ Zone Axis } \\
\hline & & & & & & & $\mathbf{X}$ & $\mathbf{Y}$ & $\mathbf{Z}$ \\
\hline$\beta-\mathrm{Bi}_{2} \mathrm{O}_{3}$ & 98.79 & 1.09 & $\left(\begin{array}{lll}2 & -1 & 0\end{array}\right)$ & 0.227 & $\left(\begin{array}{lll}0 & 1 & -2\end{array}\right)$ & 0.575 & & {$\left[\begin{array}{lll}1 & 2 & 1\end{array}\right]$} & \\
\hline$\beta-\mathrm{Bi}_{2} \mathrm{O}_{3}$ & 98.79 & 1.09 & $\left(\begin{array}{lll}2 & -1 & 0\end{array}\right)$ & 0.227 & $\left(\begin{array}{lll}0 & 1 & 2\end{array}\right)$ & 0.575 & & {$\left[\begin{array}{lll}-1 & -2 & 1\end{array}\right]$} & \\
\hline$\beta-\mathrm{Bi}_{2} \mathrm{O}_{3}$ & 98.79 & 1.09 & $\left(\begin{array}{lll}-2 & -1 & 0\end{array}\right)$ & 0.227 & $\left(\begin{array}{lll}0 & 1 & 2\end{array}\right)$ & 0.575 & & {$\left[\begin{array}{lll}1 & -2 & 1\end{array}\right]$} & \\
\hline$\beta-\mathrm{Bi}_{2} \mathrm{O}_{3}$ & 98.79 & 1.09 & $\left(\begin{array}{lll}2 & 1 & 0\end{array}\right)$ & 0.227 & $(0-12)$ & 0.575 & & {$\left[\begin{array}{lll}-1 & 2 & 1\end{array}\right]$} & \\
\hline$\beta-\mathrm{Bi}_{2} \mathrm{O}_{3}$ & 98.79 & 1.09 & $\left(\begin{array}{lll}-2 & 1 & 0\end{array}\right)$ & 0.227 & $(0-12)$ & 0.575 & & {$\left[\begin{array}{lll}1 & 2 & 1\end{array}\right]$} & \\
\hline$\beta-\mathrm{Bi}_{2} \mathrm{O}_{3}$ & 98.79 & 1.09 & $\left(\begin{array}{lll}2 & -1 & 0\end{array}\right)$ & 0.227 & $\left(\begin{array}{lll}0 & 1 & -2\end{array}\right)$ & 0.575 & & {$\left[\begin{array}{lll}1 & 2 & 1\end{array}\right]$} & \\
\hline$\beta-\mathrm{Bi}_{2} \mathrm{O}_{3}$ & 98.79 & 1.09 & $\left(\begin{array}{lll}-2 & -1 & 0\end{array}\right)$ & 0.227 & $\left(\begin{array}{lll}0 & 1 & -2\end{array}\right)$ & 0.575 & & {$\left[\begin{array}{lll}-1 & 2 & 1\end{array}\right]$} & \\
\hline$\beta-\mathrm{Bi}_{2} \mathrm{O}_{3}$ & 98.79 & 1.09 & $\left(\begin{array}{lll}2 & 1 & 0\end{array}\right)$ & 0.227 & $(0-1-2)$ & 0.575 & & {$\left[\begin{array}{lll}1 & -2 & 1\end{array}\right]$} & \\
\hline$\beta-\mathrm{Bi}_{2} \mathrm{O}_{3}$ & 98.79 & 1.09 & $\left(\begin{array}{lll}-1 & 2 & 0\end{array}\right)$ & 0.227 & $\left(\begin{array}{lll}1 & 0 & -2\end{array}\right)$ & 0.575 & & {$\left[\begin{array}{lll}2 & 1 & 1\end{array}\right]$} & \\
\hline$\beta-\mathrm{Bi}_{2} \mathrm{O}_{3}$ & 98.79 & 1.09 & $\left(\begin{array}{lll}1 & 2 & 0\end{array}\right)$ & 0.227 & $\left(\begin{array}{lll}-1 & 0 & 2\end{array}\right)$ & 0.575 & & {$\left[\begin{array}{lll}2 & -1 & 1\end{array}\right]$} & \\
\hline$\beta-\mathrm{Bi}_{2} \mathrm{O}_{3}$ & 98.79 & 1.09 & $\left(\begin{array}{lll}1 & 2 & 0\end{array}\right)$ & 0.227 & $\left(\begin{array}{lll}-1 & 0 & -2\end{array}\right)$ & 0.575 & & {$\left[\begin{array}{lll}-2 & 1 & 1\end{array}\right]$} & \\
\hline$\beta-\mathrm{Bi}_{2} \mathrm{O}_{3}$ & 98.79 & 1.09 & $\left(\begin{array}{lll}-1 & 2 & 0\end{array}\right)$ & 0.227 & $\left(\begin{array}{lll}1 & 0 & 2\end{array}\right)$ & 0.575 & & {$\left[\begin{array}{lll}-2 & -1 & 1\end{array}\right]$} & \\
\hline$\beta-\mathrm{Bi}_{2} \mathrm{O}_{3}$ & 98.79 & 1.09 & $\left(\begin{array}{lll}1 & -2 & 0\end{array}\right)$ & 0.227 & $\left(\begin{array}{lll}-1 & 0 & -2\end{array}\right)$ & 0.575 & & {$\left[\begin{array}{lll}2 & 1 & 1\end{array}\right]$} & \\
\hline$\beta-\mathrm{Bi}_{2} \mathrm{O}_{3}$ & 98.79 & 1.09 & $\left(\begin{array}{lll}1 & -2 & 0\end{array}\right)$ & 0.227 & $\left(\begin{array}{lll}-1 & 0 & -2\end{array}\right)$ & 0.575 & & {$\left[\begin{array}{lll}-2 & -1 & 1\end{array}\right]$} & \\
\hline$\beta-\mathrm{Bi}_{2} \mathrm{O}_{3}$ & 98.79 & 1.09 & $(-1-20)$ & 0.227 & $\left(\begin{array}{lll}1 & 0 & 2\end{array}\right)$ & 0.575 & & {$\left[\begin{array}{lll}-2 & -1 & 1\end{array}\right]$} & \\
\hline$\beta-\mathrm{Bi}_{2} \mathrm{O}_{3}$ & 98.79 & 1.09 & $(-1-20)$ & 0.227 & $\left(\begin{array}{lll}1 & 0 & -2\end{array}\right)$ & 0.575 & & {$\left[\begin{array}{lll}2 & -1 & 1\end{array}\right]$} & \\
\hline
\end{tabular}

only two phases. X-Ray diffraction results pointed out that the predominant bismuth oxide in the sample correspond to the $\beta-\mathrm{Bi}_{2} \mathrm{O}_{3}$. Therefore, the use of complementary information allowed to discern between those proposed solutions. Several studies on bismuth oxide polymorphs have been reported and it is known that in bulk, $\beta$ - $\mathrm{Bi}_{2} \mathrm{O}_{3}$ is metastable; however, this phase has been observed at the nanoscale level [26]-[28].

Once the phase has been determined we see, Table 1, that there are two possible zone axes: [121] and [211].

To compare this result HRTEM images were simulated by using Simula TEM software. In Figure 3(A) starting with the unit cell for $\beta$ - $\mathrm{Bi}_{2} \mathrm{O}_{3}$ [29], we construct a super cell (Figure 3(B) and finally larger nanoparticle with the help of Materials Studio till we get a cuboctahedral shape with 24425 atoms and $10.86 \mathrm{~nm}$ width, as shown in Figure 3(C).

Once the structure is obtained, the cluster is rotated to any desired zone axis; given that the positions $(x, y, z)$ and atomic numbers of all the atoms are known SimulaTEM can be used with the parameters describing the actual microscope operation. The experimental image is shown in Figure 2 and the microscope parameters are enlisted in Table 2. The starting point for the focal series was taken to be the Scherzer defocus condition.

The focal series can be seen in Figures 4(A)-(C) for [121]. Figures 4(D)-(F) focal series for [211] in comparison with Figure 2 shows that the best visual fit is to a [121] zone axis orientation.

In Figure 5(A), the experimental HREM is shown together with the simulated images Figure 5(B) and its simulated diffraction pattern, Figure 5(C).

So far the phase and the zone axis have been determined and it only remains to complete the indexing of the points in the diffractogram. CaRiNe software was employed for comparison.

The final result is shown in Figure 6, where we display the indexed diffraction pattern for a $\beta-\mathrm{Bi}_{2} \mathrm{O}_{3}$ (Tetragonal) structure. The points $d_{1}$ and $d_{2}$ from the diffractogram correspond to the planes $(-210)$ and $(0-12)$ respectively. In Figure 7, the X-ray diffraction pattern confirms the presence of $\beta-\mathrm{Bi}_{2} \mathrm{O}_{3}$ which corresponds to ICDD:PDF-2 card 00-0027-0050. In addition to this phase $\mathrm{NaNO}_{3}$ (Nitratine) is detected (PDF-2 card 00-0361474). The characterization of the particle has been completed. 


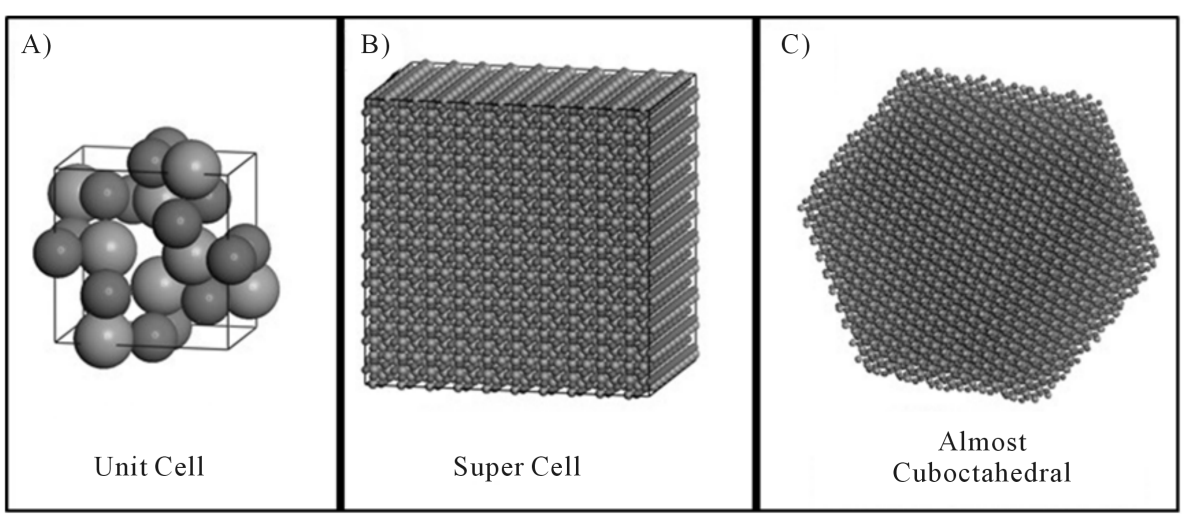

Figure 3. (A) Unit cell of $\beta$ - $\mathrm{Bi}_{2} \mathrm{O}_{3}$; (B) Super cell; (C) The cluster thus generated.
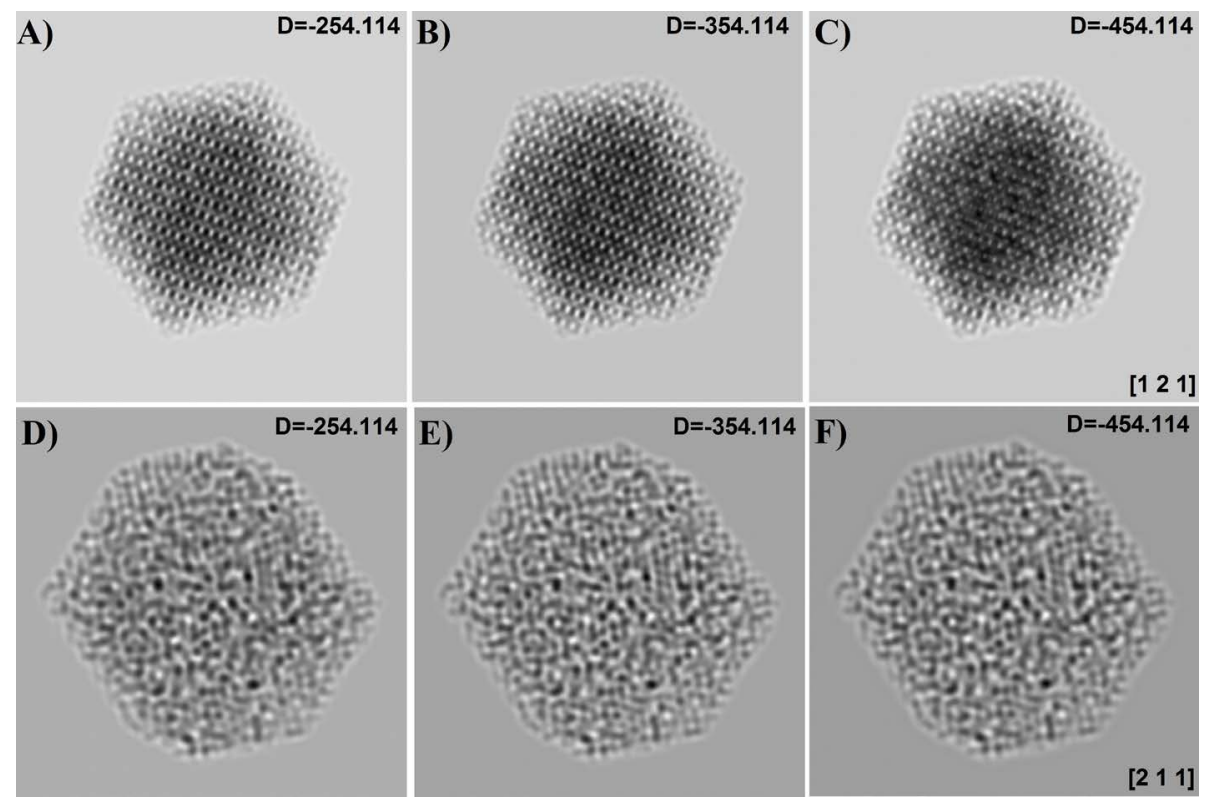

Figure 4. (A)-(C) Simulated focal series for the [121]; (D)-(F) [211] zone axes around the Scherzer condition (central images ((B) and (E)).

Table 2. Parameters used with SimulaTEM for both [121] and [211] zone axes, F2 and F5 corresponds to the Scherzer condition for [121] and [211] respectively.

\begin{tabular}{ccccccc}
\hline Microscope 2010F & F1 & F2 & F3 & F4 & F5 & F6 \\
\hline Voltage $(\mathrm{kV})$ & 200 & 200 & 200 & 200 & 200 & 200 \\
Cs. Spherical aberration (mm) & 0.5 & 0.5 & 0.5 & 0.5 & 0.5 & 0.5 \\
Defocus spread $(\AA)$ & 199 & 199 & 199 & 199 & 199 & 199 \\
Beam spread $(\AA)$ & 0.1 & 0.1 & 0.1 & 0.1 & 0.1 & 0.1 \\
Defocus $(\AA)$ & -254 & -354 & -454 & -254 & -354 & -454 \\
Astigmatism $(\AA)$ & 0 & 0 & 0 & 0 & 0 & 0 \\
Astigmatism azimut (degrees) & 30 & 30 & 30 & 30 & 30 & 30 \\
Image width $(\AA)$ & 173.5 & 173.5 & 173.5 & 173.5 & 173.5 & 173.5 \\
Slice width $(\AA)$ & 2 & 2 & 2 & 2 & 2 & 2 \\
Number of slices & 49 & 49 & 49 & 49 & 49 & 49 \\
\hline
\end{tabular}




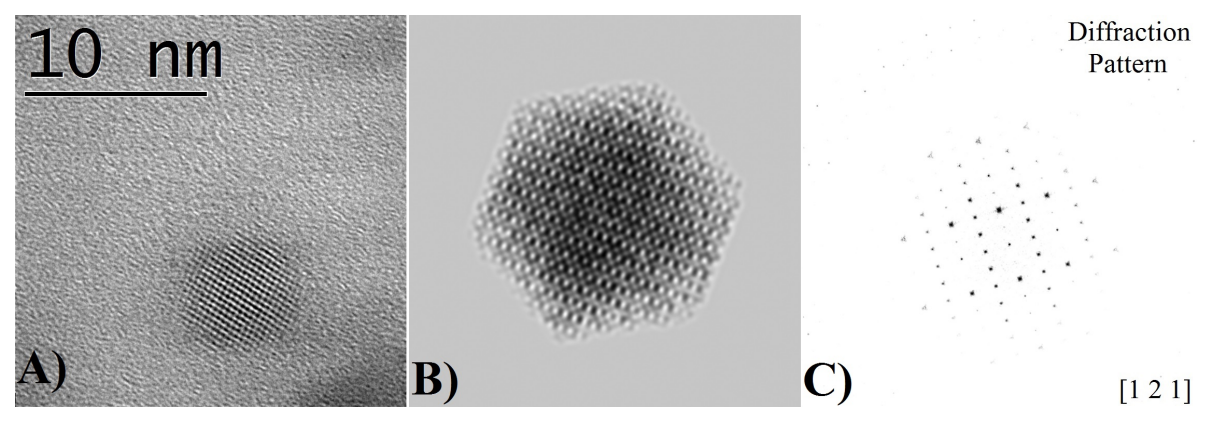

Figure 5. (A) The HREM image; (B) The simulated image (Scherzer condition); and (C) The calculated diffraction pattern.

Zone Axis: [ $\left.\begin{array}{lll}1 & 2 & 1\end{array}\right]$

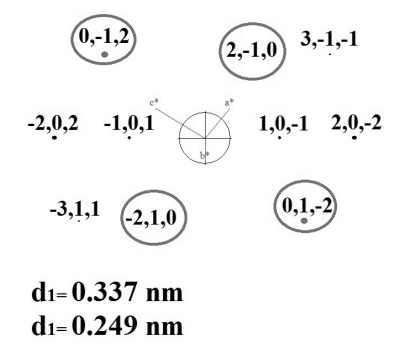

Angle between $\left(\begin{array}{lll}2 & -1 & 0\end{array}\right) /\left(\begin{array}{ll}0 & 1\end{array}-2\right)=98.61^{\circ}$

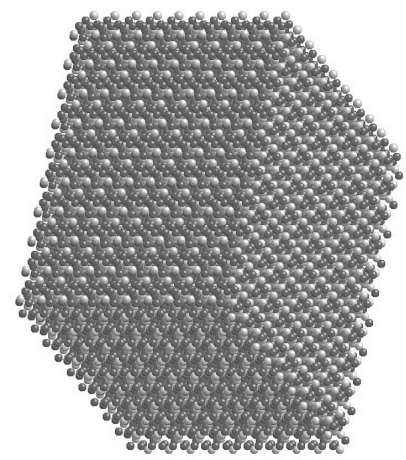

Figure 6. The geometry of the diffraction pattern (left) and of the structure.

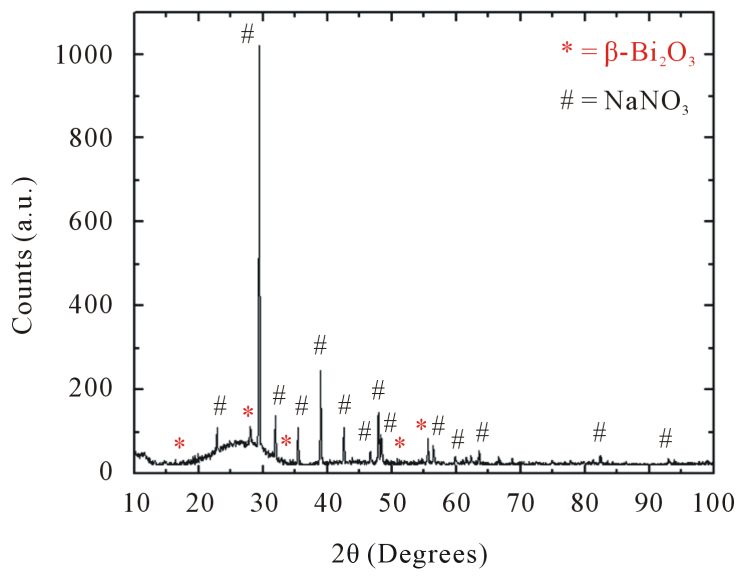

Figure 7. X-ray diffraction spectrum. The presence of $\beta-\mathrm{Bi}_{2} \mathrm{O}_{3}$ is confirmed. In the sample besides $\beta-\mathrm{Bi}_{2} \mathrm{O}_{3}$ we see Nitratine, this phase is due to the $\mathrm{NaOH}$ used to vary the $\mathrm{pH}$.

\section{Conclusions}

A protocol for structural characterization of nanoparticles based in high resolution TEM images was described. High resolution images must be Fourier-transformed to obtain reciprocal space information, in general a direct electron diffraction pattern is difficult (but not impossible) to obtain for particles in this size range. These diffractograms together with $\mathrm{x}$-ray spectra (necessarily from large samples) represent an excellent option for the identification of the phase. The images provide information on the shape (habit) of the nanoparticles, indicates whether they are single crystals or twins or if there are structural defects such as stacking faults or dislocations. Working with many particles provides size distributions. Greater certainty is provided from the comparison between actual and simulated images and diffraction patterns. 
Although the X-ray spectrum indicates the presence of $\beta-\mathrm{Bi}_{2} \mathrm{O}_{3}$ only the detailed analysis we have presented confirms that a given particle is (or is not) $\beta$ - $\mathrm{Bi}_{2} \mathrm{O}_{3}$. Figure 1 summarizes the analysis procedure that we propose, the message being that both actual measurements and simulations complement each other.

\section{Acknowledgements}

Our gratitude to Roberto Hernández Reyes for his aid with the Electron Microscope, Antonio Morales for X-Ray measurements at IFUNAM and to Dr. José Guadalupe Pérez for allowing us to use his licensed copy of CaRIne. The financial support from DGAPA (grant PAPIIT IN108915) is also acknowledged. Francisco M. Ascencio Aguirre thanks to CONACyT for the Ph.D. scholar fellowship.

\section{References}

[1] Cabral, C., Hernandez, R., Velasco, M. and Diaz, D. (2013) Bismuth Oxide Aqueous Colloidal Nanoparticles Inhibit Candida albicans Growth and Biofilm Formation. International Journal of Nanomedicine, 8, 1645-1652. http://dx.doi.org/10.2147/IJN.S38708

[2] Cabot, A., Marsal, A., Arbiol, J. and Morante, J. (2004) $\mathrm{Bi}_{2} \mathrm{O}_{3}$ as a Selective Sensing Material for NO Detection. Sensors and Actuators B: Chemical, 99, 74-89. http://dx.doi.org/10.1016/j.snb.2003.10.032

[3] Sammes, N., Tompsett, G., Näfe, H. and Aldinger, F. (1999) Bismuth Based Oxide Electrolytes—Structure and Ionic Conductivity. Journal of the European Ceramic Society, 19, 1801-1826. http://dx.doi.org/10.1016/S0955-2219(99)00009-6

[4] Denisov, V.N., Ivlev, A.N., Lipin, A.S., Mavrin, B.N. and Orlov, V.G. (1997) Raman Spectra and Lattice Dynamics of Single-Crystal $\alpha-\mathrm{Bi}_{2} \mathrm{O}_{3}$. Journal of Physics: Condensed Matter, 4967-4978. http://dx.doi.org/10.1088/0953-8984/9/23/020

[5] Liu, X.Y., Liu, J., Zheng, H.W., Liu, X.S., Li, G. and Zhang, W.F. (2012) Separation Mechanism of Photogenerated Charges for $p$-Type $\alpha-\mathrm{Bi}_{2} \mathrm{O}_{3}$ Nanoparticles with Surface States. Applied Surface Science, 258, 4240-4245. http://dx.doi.org/10.1016/j.apsusc.2011.12.059

[6] Gondal, M., Saleh, T. and Drmosh, Q. (2012) Optical Properties of Bismuth Oxide Nanoparticles Synthesized by Pulsed Laser Ablation in Liquids. Science of Advanced Materials, 4, 507-510. http://dx.doi.org/10.1166/sam.2012.1310

[7] Lin, G., Tan, D.Z., Luo, F.F., Chen, D.P., Zhao, Q.Z., Qiu, J.R. and Xu, Z.Z. (2010) Fabrication and Photocatalytic Property of $\alpha-\mathrm{Bi}_{2} \mathrm{O}_{3}$ Nanoparticles by Femtosecond Laser Ablation in Liquid. Journal of Alloys and Compounds, 507, L43-L46. http://dx.doi.org/10.1016/j.jallcom.2010.08.014

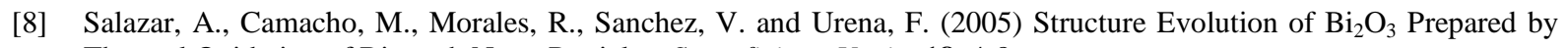
Thermal Oxidation of Bismuth Nano-Particles. Superficies y Vacio, 18, 4-8.

[9] Bartonickova, E., Cihlar, J. and Castkova, K. (2007) Microwave-Assisted Synthesis of Bismuth Oxide. Processing and Application of Ceramics, 1, 29-33. http://dx.doi.org/10.2298/PAC0702029B

[10] Dong, W. and Zhu, C. (2003) Optical Properties of Surface-Modified $\mathrm{Bi}_{2} \mathrm{O}_{3}$ Nanoparticles. Journal of Physics and Chemistry of Solids, 64, 265-271. http://dx.doi.org/10.1016/S0022-3697(02)00291-3

[11] Li, W. (2006) Facile Synthesis of Monodisperse $\mathrm{Bi}_{2} \mathrm{O}_{3}$ Nanoparticles. Materials Chemistry and Physics, 99, $174-180$. http://dx.doi.org/10.1016/j.matchemphys.2005.11.007

[12] Ascencio, A.F.M. and Becerra, R.H. (2015) New Synthesis of Bismuth Oxide Nanoparticles $\mathrm{Bi}_{2} \mathrm{O}_{3}$ Assisted by Tannic Acid. Applied Physics A, 119, 909-915. http://dx.doi.org/10.1007/s00339-015-9039-x

[13] Abdelwahed, W., Degobert, G., Stainmesse, S. and Fessi, H. (2006) Freeze-Drying of Nanoparticles: Formulation, Process and Storage Considerations. Advanced Drug Delivery Reviews, 58, 1688-1713.

http://dx.doi.org/10.1016/j.addr.2006.09.017

[14] Galicia, R., Herrera, R., Rius, J., Zorrilla, C. and Gómez, A. (2013) A Program for Phase Identification Using Diffractograms Obtained from TEM Structure Images. Revista Mexicana de Física, 59, 102-106.

[15] Gómez-Rodríguez, A., Beltrán-del-Río, L.M. and Herrera-Becerra, R. (2010) SimulaTEM: Multislice Simulations for General Objects. Ultramicroscopy, 110, 95-104. http://dx.doi.org/10.1016/j.ultramic.2009.09.010

[16] Cowley, J.M. and Moodie, A.F. (1957) The Scattering of Electrons by Atoms and Crystals. I. A New Theoretical Approach. Acta Crystallographica, 10, 609-619. http://dx.doi.org/10.1107/S0365110X57002194

[17] Risold, D., Hallstedt, B., Gauckler, L., Lukas, H. and Fries, S. (1995) The Bismuth-Oxygen System. Journal of Phase Equilibria, 16, 223-234. http://dx.doi.org/10.1007/BF02667306

[18] Drache, M., Roussel, P. and Wignacourt, J. (2007) Structures and Oxide Mobility in Bi-Ln-O Materials: Heritage of 
$\mathrm{Bi}_{2} \mathrm{O}_{3}$. Chemical Reviews, 107, 80-96. http://dx.doi.org/10.1021/cr050977s

[19] Kumada, N., Kinomura, N., Woodward, P. and Sleight, A.W. (1995) Crystal Structure of $\mathrm{Bi}_{2} \mathrm{O}_{4}$ with $_{\beta}$-Sb $\mathrm{S}_{2} \mathrm{O}_{4}$-Type Structure. Journal of Solid State Chemistry, 116, 281-285. http://dx.doi.org/10.1006/jssc.1995.1214

[20] Xia, J.-Y., Tang, M., Chen, C., Jin, S. and Chen, Y. (2012) Preparation of $\alpha-\mathrm{Bi}_{2} \mathrm{O}_{3}$ from Bismuth Powders through Low-Temperature Oxidation. Transactions of Nonferrous Metals Society of China, 22, 2289-2294. http://dx.doi.org/10.1016/S1003-6326(11)61462-3

[21] Blower, S. and Greaves, C. (1988) The Structure of $\beta-\mathrm{Bi}_{2} \mathrm{O}_{3}$ from Powder Neutron Diffraction Data. Acta Crystallographica Section C: Crystal Structure Communications, 44, 587-589. http://dx.doi.org/10.1107/S0108270187011661

[22] Radaev, S.F., Simonov, V.I. and Kargin, Y.F. (1992) Structural Features of $\gamma$-Phase $\mathrm{Bi}_{2} \mathrm{O}_{3}$ and Its Place in the Sillenite Family. Acta Crystallographica Section B, 48, 604-609. http://dx.doi.org/10.1107/S0108768192003847

[23] Battlet, P., Catlow, C., Drennans, J. and Murray, A. (1983) The Structural Properties of the Oxygen Conducting $\delta$ Phase of $\mathrm{Bi}_{2} \mathrm{O}_{3}$. Journal of Physics C: Solid State Physics, 16, L561-L566. http://dx.doi.org/10.1088/0022-3719/16/17/003

[24] Atou, T., Faqir, H., Kikuchi, M., Chiba, H. and Syono, Y. (1998) A New High-Pressure Phase of Bismuth Oxide. Materials Research Bulletin, 33, 289-292. http://dx.doi.org/10.1016/S0025-5408(97)00216-X

[25] Brugger, R.M., Bennion, R.B. and Worlton, T.G. (1967) The Crystal Structure of Bismuth-II at 26 Kbar. Physics Letters A, 24, 714-717. http://dx.doi.org/10.1016/0375-9601(67)90230-7

[26] Guenther, G., Kruis, F.E. and Guillon, O. (2014) Size-Dependent Phase Transformations in Bismuth Oxide Nanoparticles. I. Synthesis and Evaporation. The Journal of Physical Chemistry C, 118, 27010-27019.

[27] Guenther, G., Theissmann, R. and Guillon, O. (2014) Size-Dependent Phase Transformations in Bismuth Oxide Nanoparticles. II. Melting and Stability Diagram. The Journal of Physical Chemistry C, 118, 27020-27027. http://dx.doi.org/10.1021/jp509841s

[28] Steele, J.A. and Lewis, R.A. (2014) In Situ Micro-Raman Studies of Laser-Induced Bismuth Oxidation Reveals Metastability of Beta- $\mathrm{Bi}_{2} \mathrm{O}_{3}$ Microislands. Optical Materials Express, 4, 2133-2144.

[29] Deng, Y.H., Cai, Y., Sun, Z.K. and Zhao, D.Y. (2011) Magnetically Responsive Ordered Mesoporous Materials: A Burgeoning Family of Functional Composite Nanomaterials. Chemical Physics Letters, 510, 1-13. http://dx.doi.org/10.1016/j.cplett.2011.04.093 